University of Montana

ScholarWorks at University of Montana

Integrative Physiology and Athletic Training

Faculty Publications

Integrative Physiology and Athletic Training

4-2013

\title{
Environmental Temperature and Exercise-Induced Blood Oxidative Stress
}

John C. Quindry

Auburn University Main Campus

Lindsey Miller

Auburn University Main Campus

Graham McGinnis

Auburn University Main Campus

Brian Kliszczewiscz

Auburn University Main Campus

Dustin R. Slivka

University of Nebraska at Omaha

See next page for additional authors

Follow this and additional works at: https://scholarworks.umt.edu/hhp_pubs

Part of the Medicine and Health Sciences Commons

Let us know how access to this document benefits you.

\section{Recommended Citation}

Quindry, John C.; Miller, Lindsey; McGinnis, Graham; Kliszczewiscz, Brian; Slivka, Dustin R.; Dumke, Charles; Cuddy, John S.; and Ruby, Brent, "Environmental Temperature and Exercise-Induced Blood Oxidative Stress" (2013). Integrative Physiology and Athletic Training Faculty Publications. 12.

https://scholarworks.umt.edu/hhp_pubs/12

This Article is brought to you for free and open access by the Integrative Physiology and Athletic Training at ScholarWorks at University of Montana. It has been accepted for inclusion in Integrative Physiology and Athletic Training Faculty Publications by an authorized administrator of ScholarWorks at University of Montana. For more information, please contact scholarworks@mso.umt.edu. 


\section{Authors}

John C. Quindry, Lindsey Miller, Graham McGinnis, Brian Kliszczewiscz, Dustin R. Slivka, Charles Dumke, John S. Cuddy, and Brent Ruby 


\title{
Environmental Temperature and Exercise-Induced Blood Oxidative Stress
}

\author{
John Quindry, Lindsey Miller, Graham McGinnis, Brian Kliszczewiscz, Dustin Slivka, \\ Charles Dumke, John Cuddy, and Brent Ruby
}

\begin{abstract}
Previous research findings indicate that environmental temperature can influence exercise-induced oxidativestress responses, although the response to variable temperatures is unknown. The purpose of this study was to investigate the effect of warm, cold, and "neutral," or room, environmental temperatures on the blood oxidative stress associated with exercise and recovery. Participants $\left(N=12\right.$, age $27 \pm 5 \mathrm{yr}, \mathrm{VO}_{2 \max }=56.7 \pm 5.8 \mathrm{ml} \cdot \mathrm{kg}^{-1}$ $\cdot$ min $^{-1}$, maximal cycle power output $=300 \pm 39 \mathrm{~W}$ ) completed 3 exercise sessions consisting of a 1-hr ride at $60 \% \mathrm{~W}_{\max }$, at $40 \%$ relative humidity in warm $\left(33^{\circ} \mathrm{C}\right)$, cold $\left(7^{\circ} \mathrm{C}\right)$, and room-temperature environments $(20$ ${ }^{\circ} \mathrm{C}$ ) in a randomized crossover fashion. Rectal core temperature was monitored continually as participants remained in the respective trial temperature throughout a 3-hr recovery. Blood was collected preexercise and immediately, $1 \mathrm{hr}$, and $3 \mathrm{hr}$ postexercise and analyzed for oxidative-stress markers including ferric-reducing ability of plasma (FRAP), Trolox-equivalent antioxidant capacity (TEAC), lipid hydroperoxides, and protein carbonyls. Core temperature was significantly elevated by all exercise trials, but recovery core temperatures reflected the given environment. FRAP $(p<.001)$, TEAC $(p<.001)$, and lipid hydroperoxides $(p<.001)$ were elevated after warm exercise while protein carbonyls were not altered $(p>.05)$. These findings indicate that moderate-intensity exercise and associated recovery in a warm environment elicits a blood oxidative-stress response not observed at comparable exercise performed at lower temperatures.
\end{abstract}

Keywords: antioxidant capacity, free radicals, protein carbonyls, reactive oxygen species

Numerous research reports demonstrate that reduction-oxidation (redox) perturbations are part of the acute exercise stimulus (Gomez-Cabrera et al., 2005; GomezCabrera, Domenech, \& Vina, 2008; Hudson et al., 2008; McAnulty et al., 2005; McAnulty et al., 2007; Quindry et al., 2008; Quindry, Stone, King, \& Broeder, 2003). Redox stress responses are loosely called oxidative stress, although this term is increasingly scrutinized in the context of exercise (Jones, 2006) where redox perturbations stimulate many beneficial adaptations (Gomez-Cabrera et al., 2005; Gomez-Cabrera et al., 2008; Ristow et al., 2009; Vina, Borras, Gomez-Cabrera, \& Orr, 2006; Vina et al., 2000). Recent investigations reveal that ambient temperature may influence the exercise-induced oxidative-stress response (Gomes, Stone, \& Florida-James, 2011; Laitano, Kalsi, Pook, Oliveira, \& Gonzalez-Alonso, 2010; McAnulty et al., 2005; Salo, Donovan, \& Davies, 1991).

McAnulty et al. (2005) found that treadmill running produced significant core temperature elevations $(39.5$

Quindry, Miller, McGinnis, and Kliszczewiscz are with the Dept. of Kinesiology, Auburn University, Auburn AL. Slivka is with the School of Health, Physical Education and Recreation, University of Nebraska at Omaha, Omaha, NE. Dumke, Cuddy, and Ruby are with the Dept. of Health and Human Performance, University of Montana, Missoula, MT.
${ }^{\circ} \mathrm{C}$ ) and elicited a significant rise in a plasma $\mathrm{F}_{2}$-isoprostanes, while comparable exercise without an elevation in core temperature did not. Given that core temperature during cool-environment exercise can elevate by several degrees Celsius, the impact of the environment on exercise commonly performed for improved health and fitness is currently unknown. Another previous investigation was undertaken to understand the independent contribution of $1{ }^{\circ} \mathrm{C}$ increase in core temperature versus hydration status on exercise-induced oxidative stress (Laitano et al., 2010). Core temperature was manipulated as participants wore a temperature-controlled water-perfused vest during onelegged knee-extensor exercise performed in dehydrated and euhydrated conditions. Findings from euhydrated participants suggest that elevated core temperature is independently associated with a rise in postexercise blood oxidative stress, although the influence of multiple environmental temperatures on exercise-induced oxidative stress is unknown (Laitano et al., 2010).

Given these unknowns, the current investigation was undertaken to understand the influence of warmenvironment $\left(33{ }^{\circ} \mathrm{C}\right)$ cycle-ergometer exercise on oxidative stress with two comparable sessions in cooler ambient conditions $\left(7{ }^{\circ} \mathrm{C}\right.$ and $\left.20{ }^{\circ} \mathrm{C}\right)$. Because of the need to understand oxidative-stress responses in applied physiology settings, the cycle protocol used $60 \mathrm{~min}$ of moderate-intensity steady-state exercise, which resulted 
in an elevated core temperature for all trials. An additional novel feature of the current study's design was that the respective environmental temperatures were extended into a 3-hr exercise-recovery period. Finally, blood oxidative stress was quantified using a panel of oxidative-stress biomarkers intended to encompass the dynamic biological milieu of human blood plasma. This panel included two markers for plasma antioxidant potential in addition to lipid- and protein-based markers of oxidative damage. This approach collectively accounts for aqueous- and lipid-phase antioxidants of protein and nonprotein composition in addition to alterations in oxidative-damage markers (Buettner, 1993; Cao \& Prior, 1998). We hypothesized that core temperature would be elevated by all environmental temperatures and that the blood oxidative-stress response to warm-environment $\left(33{ }^{\circ} \mathrm{C}\right)$ exercise would be higher than cold and roomtemperature $\left(7^{\circ} \mathrm{C}\right.$ and $\left.20^{\circ} \mathrm{C}\right)$ conditions.

\section{Methods}

\section{Subjects}

The study was approved by the University of Montana's institutional review board, and signed informed consent was obtained from each subject before data collection. Twelve recreationally active male subjects were recruited for this investigation. They completed a Physical Activity Readiness Questionnaire (PAR-Q) and were oriented to the experimental protocol. Subjects' body composition was determined by hydrostatic weighing, with corrections for estimated individual variance in residual lung volume included. Individuals currently taking supplemental vitamins or antioxidant supplements were excluded from the study. Subjects were instructed to abstain from NSAIDs and exercise during and $24 \mathrm{hr}$ before exercise testing. If subjects chose to exercise in the $48 \mathrm{hr}$ before exercise testing, they were instructed to perform identical exercise bouts in the days before testing. In an attempt to standardize dietary intakes, participants were instructed to consume the same foods in identical quantities during the $24 \mathrm{hr}$ leading up to the three exercise sessions.

\section{Maximal Exercise Capacity}

Maximal oxygen consumption $\left(\mathrm{VO}_{2 \max }\right)$ and associated workloads $\left(\mathrm{W}_{\max }\right)$ were measured for each subject on an electrically braked cycle ergometer (Computrainer, RacerMate Inc., Seattle, WA). The maximal exercise protocol began with an initial workload of $95 \mathrm{~W}$ and continued in $35-\mathrm{W}$ increments every 3 min until volitional exhaustion was achieved. $\mathrm{W}_{\max }$ was calculated as the highest stage completed plus the proportional work performed during the incomplete last stage. $\mathrm{VO}_{2}$ values were collected on a calibrated metabolic cart (Parvomedics, Inc., Salt Lake City, UT) and mixing chamber. Values were calculated from expired gases and averaged over 15-s intervals.

\section{Study Design}

Subjects were instructed to report to the laboratory in a 12-hr fasted condition. The study design is presented in Figure 1. It was a randomized, counterbalanced crossover design of three exercise trials. Trials consisted of temperature- and humidity-controlled exercise ( $1 \mathrm{hr}$ ) and recovery periods $(3 \mathrm{hr}$ ) in an environmental chamber (Tescor, Warminster, PA). The three exercise trials were cold $\left(7^{\circ} \mathrm{C}\right.$, $40 \%$ humidity), room temperature $\left(20^{\circ} \mathrm{C}, 40 \%\right.$ humidity $)$, and warm $\left(33^{\circ} \mathrm{C}, 40 \%\right.$ humidity $)$. Subjects reported to the laboratory after a 12 -hr fast and having refrained from exercise for at least $24 \mathrm{hr}$. Exercise trials all involved stationarycycle exercise at $60 \%$ of $\mathrm{W}_{\max }$ in the assigned temperature and humidity condition. Exercise-chamber temperature and humidity were monitored to confirm adherence with study conditions within $1{ }^{\circ} \mathrm{C}$ and $2 \%$ humidity. Subjects rehydrated with a standard room-temperature $\mathrm{H}_{2} \mathrm{O}$ volume during exercise $(590 \mathrm{ml})$ and recovery $(590 \mathrm{ml})$ periods. They were instructed to towel-dry immediately after exercise and were provided a pair of dry cotton shorts and T-shirt to wear during recovery. Subjects remained in the supine position during the recovery period. Study trials were separated by at least 1 week.

\section{Core Temperature}

Core body temperature was monitored continually during the exercise and recovery periods with a digital

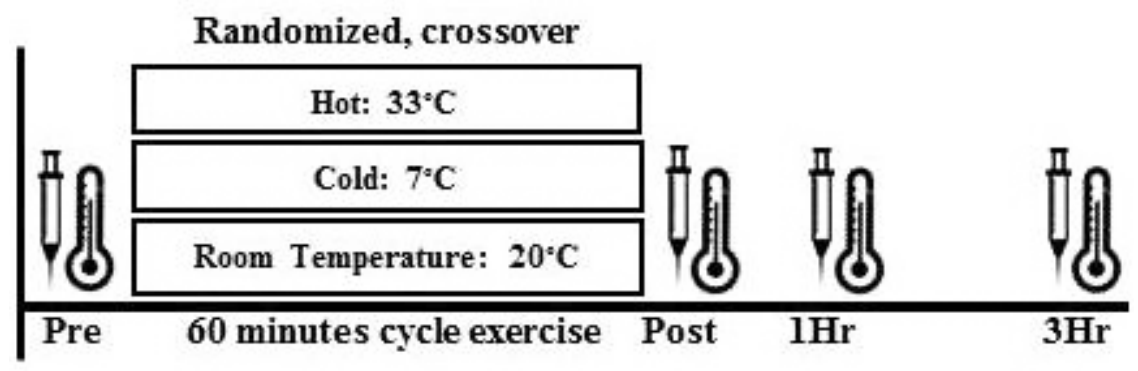

Figure 1 - Study design. Blood (syringe icon) and body core temperature (thermometer icon) were sampled before and after warm, cold, and room-temperature (randomized crossover design) exercise trials. 
data-acquisition system and rectal thermistor (Physitemp Instruments Inc., Clifton, NJ) inserted $15 \mathrm{~cm}$ past the anal sphincter.

\section{Blood Collection}

Venipuncture was performed at the antecubital vein, and blood samples were collected in heparinized tubes with participants in a seated position. Sampling time points were before exercise, immediately after exercise, $1 \mathrm{hr}$ after exercise, and $3 \mathrm{hr}$ into the postexercise recovery period. Whole-blood aliquots were used to determine hematocrit using a microhematocrit centrifuge (Jouan A13, Winchester, VA). Remaining whole blood was used to determine hemoglobin content using the colorimetric cyanmethemoglobin procedure per manufacturer instructions (Drabkin's reagent, Sigma, St. Louis, MO). Plasma-volume shifts during exercise and recovery were calculated according to an established protocol (Dill \& Costill, 1974). The blood plasma was centrifuged, aliquotted, and frozen at $-80^{\circ} \mathrm{C}$ for subsequent biochemical analyses.

\section{Plasma Oxidative-Stress Biomarkers}

Plasma aliquots were assayed for an oxidative-stress biomarker panel used previously by our group (Hudson et al., 2008; Quindry et al., 2003). Two biomarkers, plasma Trolox-equivalent antioxidant capacity (TEAC) and ferric-reducing antioxidant potential (FRAP), were chosen to evaluate blood plasma antioxidant capacity. Oxidative damage was evaluated in plasma by determination of protein carbonyls and lipid hydroperoxides content.

Plasma antioxidant capacity was measured by the plasma TEAC technique, whereby a radical cation of the 2,2'-azinobis(3-ethylbenzothiazoline-6-sulfonate) reaction is quenched by sample-specific antioxidant fortifications (Cao, Russell, Lischner, \& Prior, 1998). Total plasma antioxidant potential was determined by the FRAP assay according to the methodology of Benzie and Strain (1996). Both TEAC and FRAP assays result in quantifiable colorimetric solutions that are visualized spectrophotometrically. Lipid peroxidation was determined by the ferrous oxidation-xylenol orange assay (Nourooz-Zadeh, Tajaddini-Sarmadi, \& Wolff, 1994). In brief, ferrous ions are oxidized by lipid hydroperoxides to ferric ions and subsequently react with the ferrous-sensitive dye containing xylenol orange. In the presence of lipid hydroperoxides, this reaction forms a spectrophotometrically quantifiable complex. Protein carbonyls were analyzed using a commercially available ELISA kit (Zentech Technology, Dunedin, New Zealand). All assays were performed in triplicate and exhibited within-sample coefficients of variation of $2-5 \%$. Before analysis, all plasma samples were assayed in quadruplicate for protein concentration based on the methods of Bradford (1976) and adjusted to $4 \mathrm{mg} / \mathrm{ml}$ protein using a phosphate buffer. Each of the oxidative-stress biomarkers in our panel is sensitive to exercise applications and has been used repeatedly by our group and others as a comprehensive assessment of blood oxidative stress (McAnulty et al., 2005; McAnulty et al., 2007; Quindry et al., 2011; Quindry et al., 2008; Quindry et al., 2003). Rationale for these biomarkers is founded on the fact that oxidative stress within a body compartment, such as blood plasma, occurs according to a free-radical pecking order. In this pecking order, water-soluble antioxidants and then lipid-soluble antioxidants are oxidized before the appearance of lipid or protein oxidative-damage markers (Buettner, 1993; Frei, Stocker, \& Ames, 1988). Given this understanding, the oxidative-stress biomarker panel employed currently is sensitive to protein and nonprotein water-soluble antioxidants in addition to lipid-phase antioxidants (Cao \& Prior, 1998). All oxidative-stress biomarkers were normalized for plasma-volume changes experienced during the three trials. Plasma-volume shift estimates were based on established protocols that normalize to hemoglobin and hematocrit levels compared with preexercise for a given trial (Dill \& Costill, 1974).

\section{Statistical Analysis}

A two-way repeated-measures analysis of variance (ANOVA) was used to analyze trial differences for plasma oxidative-stress biomarkers and core-temperature data. Where appropriate, Tukey's post hoc tests were used to examine time effects. For this investigation, statistical significance was set at $p<.05$ a priori. Statistical analyses were performed using a statistical software package (Kaleidagraph, Synergy Software, Reading, PA).

\section{Results}

Participant physical characteristics and performance data are presented in Table 1. Participants were relatively lean as determined by hydrostatic weighing and were moderately fit based on maximal aerobic capacity and cycle performance data. All participants successfully completed the three trials at $60 \% \mathrm{~W}_{\max }$ with a mean oxygen consumption of $64.8 \% \pm 0.8 \% \mathrm{VO}_{2 \max }$. Coretemperature data for exercise and recovery periods are presented in Figure 2. Analysis of core-temperature data reveals significant time- $(p<.001)$ and trial-dependent $(p$

\section{Table 1 Participant Physical Characteristics,} $M \pm S E M$

\begin{tabular}{lc}
\hline Characteristic & Value \\
\hline Age $($ years $)$ & $27.1 \pm 5.0$ \\
Height $(\mathrm{cm})$ & $178.1 \pm 1.7$ \\
Body mass $(\mathrm{kg})$ & $78.1 \pm 0.3$ \\
Body fat $(\%)$ & $11.8 \pm 5.3$ \\
$\mathrm{VO}_{2 \max }\left(\mathrm{ml} \cdot \mathrm{kg}^{-1} \cdot \mathrm{min}^{-1}\right)$ & $56.7 \pm 5.8$ \\
Maximum watts $(\mathrm{W})$ & $300.0 \pm 39.0$ \\
Watts at $60 \%(\mathrm{~W})$ & $180.0 \pm 6.8$ \\
\hline
\end{tabular}




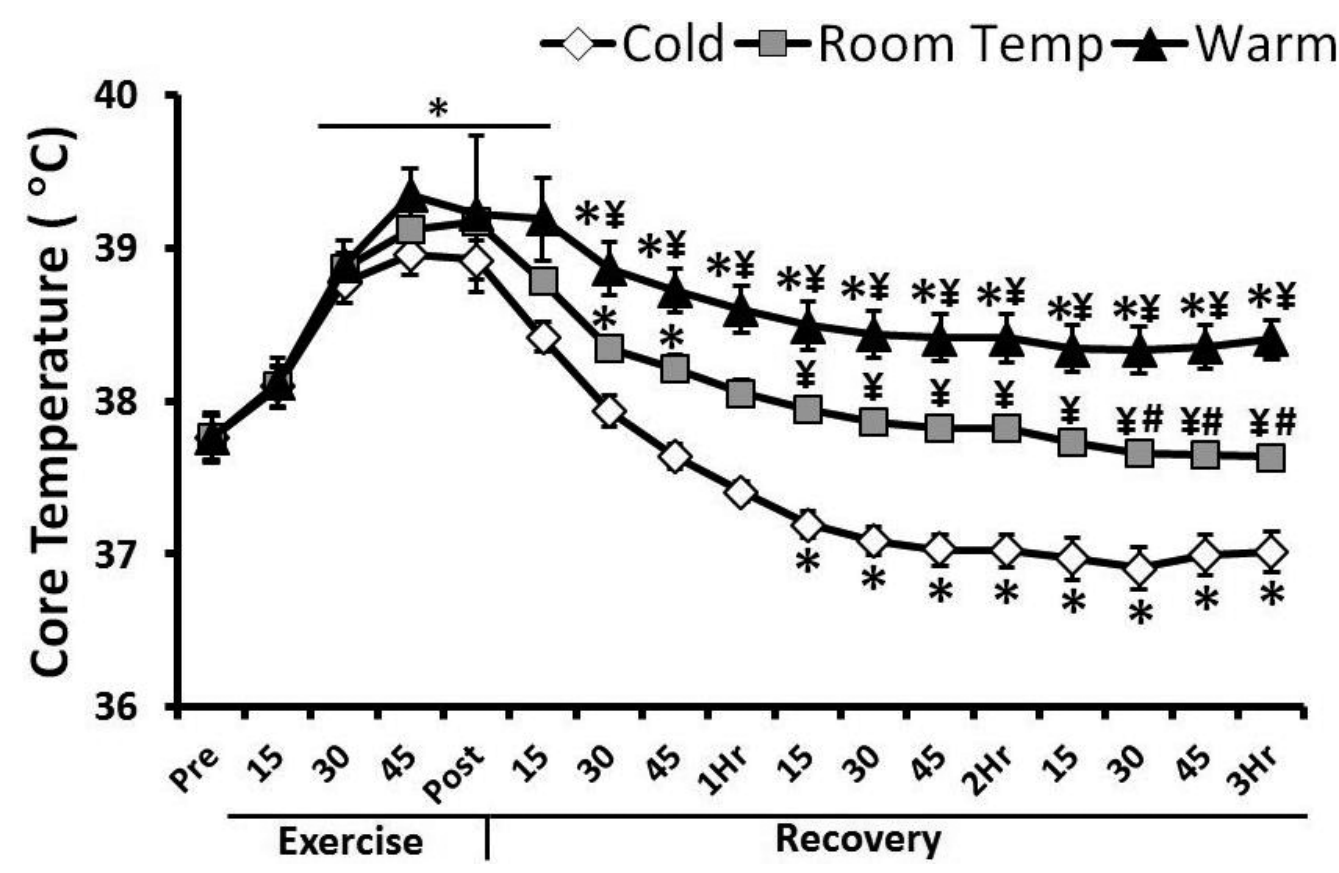

Figure 2 - Body core temperature during exercise and recovery periods, $M \pm S E M, n=12 /$ measure. Black triangles = warm trial; white diamonds = cold trial; gray squares = room-temperature trial. *Significantly different from preexercise; \#Significantly different from warm; ¥Significantly different from cold; $p \leq .05$.

$<.001)$ outcomes. Post hoc analysis indicates that warm, cold, and room-temperature exercise trials elicited a rise in core-temperature response by the end of the exercise bout. During recovery, the warm exercise trial elicited a significantly greater increase in core temperature than the cold exercise, while warm and room-temperature trial differences were observed in the final $45 \mathrm{~min}$ of exercise recovery. Cold and room-temperature trial differences were observed from 1:15 to 2:45 in the exercise recovery period.

Biomarkers for antioxidant capacity in blood plasma samples are presented for FRAP in Figure 3(a) and TEAC in Figure 3(b). Significant time- $(p<.001)$ and trial-dependent $(p=.049)$ alterations in plasma FRAP were observed in response to the three trials. Post hoc analysis of plasma FRAP revealed significant elevations during the warm trial at POST and 1-hr sample points. Plasma TEAC exhibited significant trial $(p<.001)$ and time main effects $(p=.001)$. Post hoc analysis revealed significant elevations in plasma TEAC during the warm trial at postexercise and 1-hr sampling points. Plasma TEAC values were significantly different between warm and cold trials at both the 1-hr and 3-hr time points.

Biomarkers used to assess oxidative damage are presented for blood plasma lipid hydroperoxides (Figure $4[a]$ ) and blood plasma protein carbonyl content (Figure $4[\mathrm{~b}])$. Significant time- $(p<.001)$ and trial-dependent $(p=.011)$ elevations were observed for plasma lipid hydroperoxides. Post hoc analysis indicated a significant elevation in plasma lipid hydroperoxides at the 1-hr time point for the warm trial only. At the 1-hr time point, the mean lipid hydroperoxide response was significantly different between warm and cold trials. Analysis of mean protein values revealed statistically significant main effects for time ( $p=.015)$ but not trial $(p=.244)$. This time-dependent effect for plasma protein carbonyls was confirmed by analysis $(p=.013)$ of all trial samples collapsed for the various sampling time points (data not shown). Post hoc analysis revealed elevations in plasma protein carbonyls at the $1-\mathrm{hr}(p=.039)$ and 3 -hr $(p=$ $.041)$ time points, while postexercise values approached significance $(p=.075)$ compared with preexercise.

\section{Discussion}

Hyperthermia and oxidative stress are well-described physiologic responses to acute exercise (Bergholm et al., 1999; Gomez-Cabrera et al., 2005; Gomez-Cabrera et al., 2008; Hudson et al., 2008; McAnulty et al., 2005; McAnulty et al., 2007; Quindry et al., 2008; Quindry et al., 2003). While redox perturbations due to exercise can induce damage, they also induce exercise-based adaptations (Gomez-Cabrera et al., 2005; Gomez-Cabrera et al., 2008; Ristow et al., 2009; Vina et al., 2006; Vina et al., 2000). The redox stimulus response can also be influenced by ambient environments (Gomes et al., 2011; Laitano et al., 2010; McAnulty et al., 2005; Salo et al., 1991) and may extend to postexercise recovery (Hall, Buettner, Matthes, \& Gisolfi, 1994; Mitchell \& Russo, 1983). The current study was undertaken to quantify the 

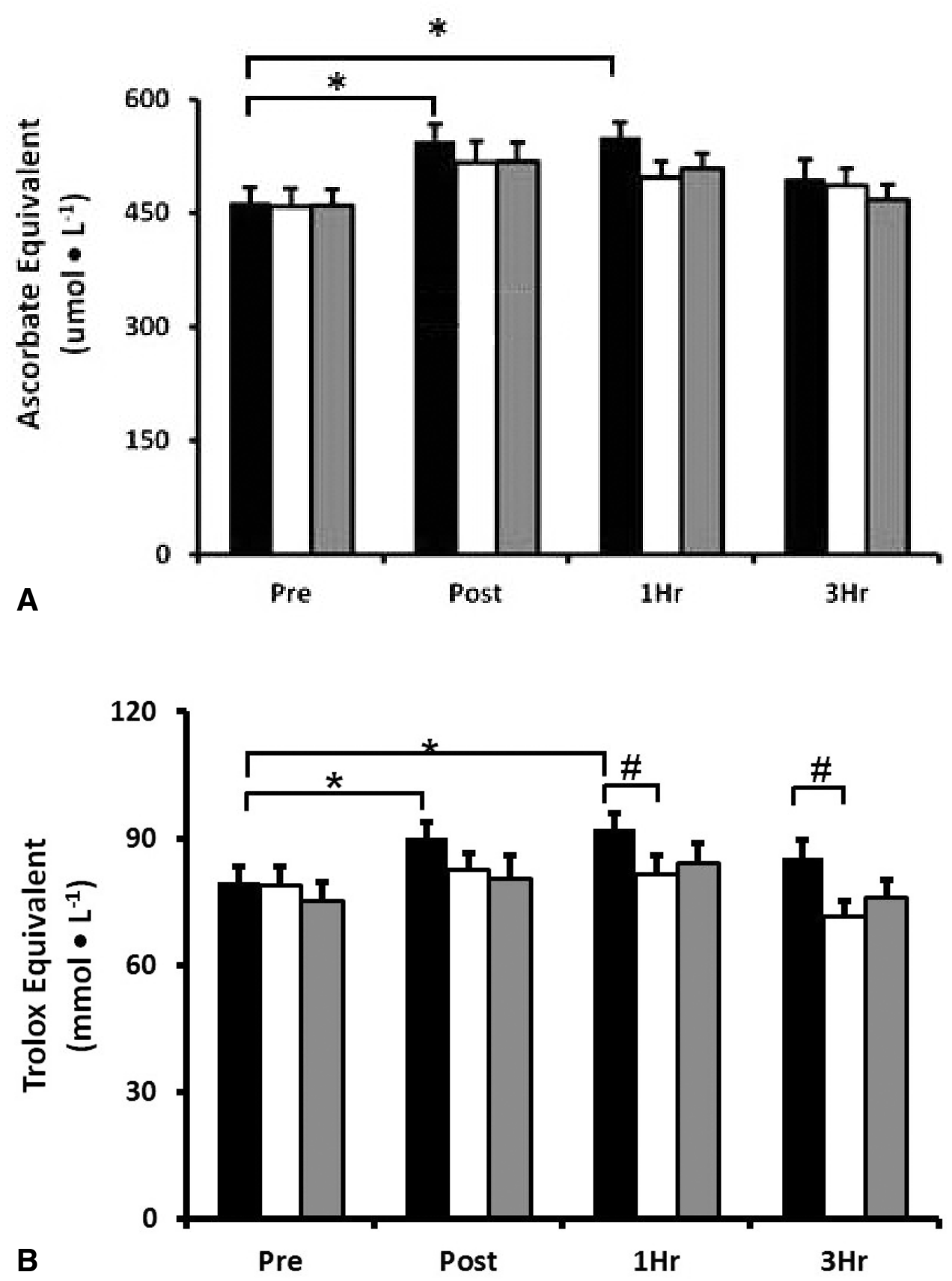

Figure 3 - Biomarkers of plasma antioxidant capacity before and after exercise, $M \pm S E M, n=12 /$ measure. (a) Ferric-reducing ability of blood plasma and (b) blood plasma Trolox-equivalent antioxidant capacity. Black bars = warm trial; white bars = cold trial; gray bars = room-temperature trial. $*$ Significantly different from preexercise values; \#Significantly different from warm; $p \leq .05$.

blood oxidative response to acute moderate-intensity cycle exercise and recovery performed in warm, cold, and room-temperature conditions. In this repeated-measures, crossover study design, participants remained in the assigned temperature condition to evaluate the evolution of the blood oxidative-stress response during the 3 -hr recovery period. Novel findings reveal that blood oxidative-stress responses to exercise recovery in a warm environment were greater than identical exerciserecovery challenges in cold or room-temperature conditions. Because energy expenditure did not differ between room-temperature and warm exercise trials, this finding suggests that core temperature may drive the differences observed in oxidative-stress biomarkers in warmer environments (data presented elsewhere; Slivka, Dumke, Tucker, Cuddy, \& Ruby, 2012). 
A
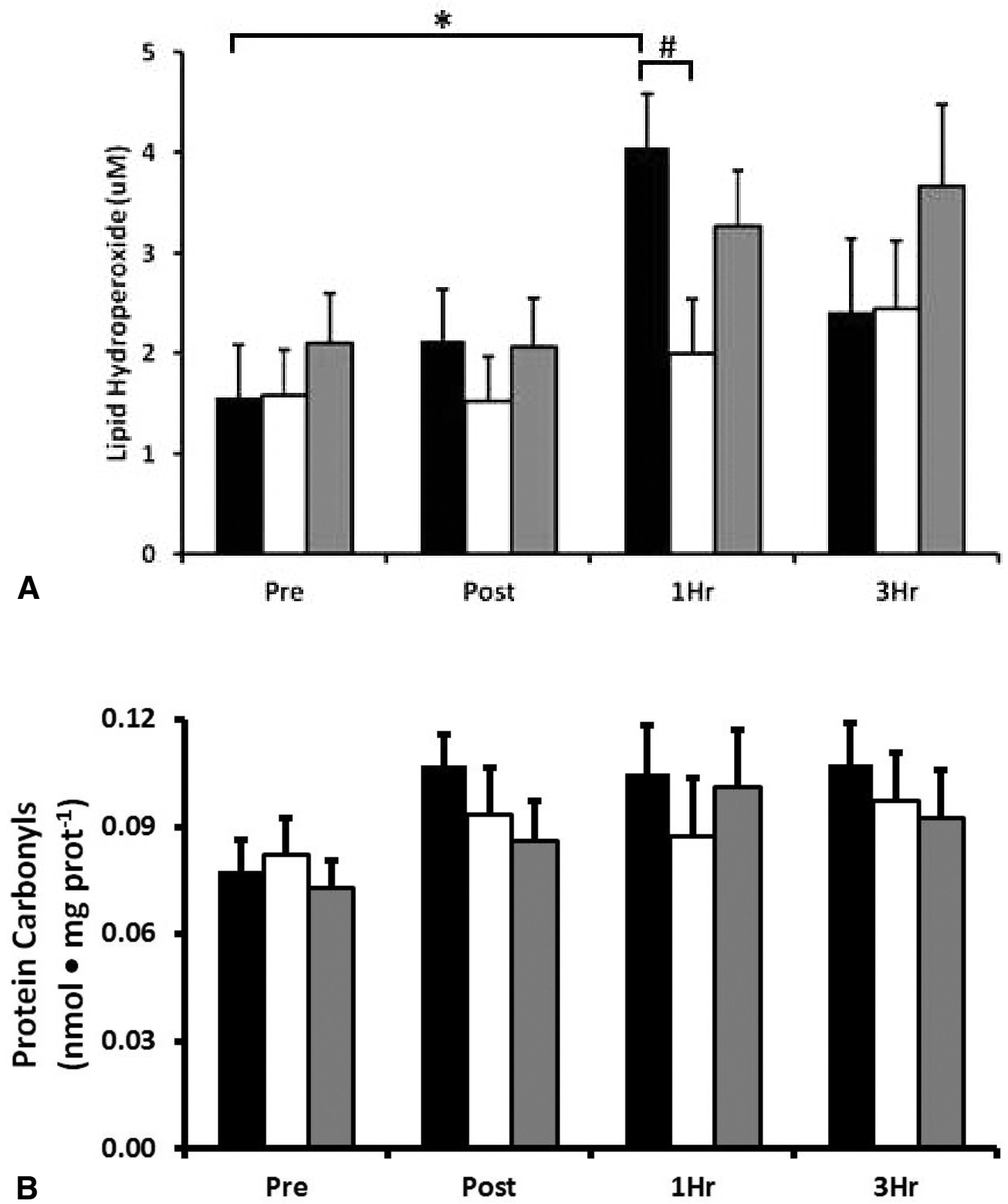

Figure 4 - Biomarkers of plasma oxidative damage, $M \pm S E M, n=12 /$ measure. (a) Blood plasma lipid hydroperoxide content before and after exercise and (b) blood plasma protein carbonyl content. Black bars = warm trial; white bars = cold trial; gray bars $=$ room-temperature trial. $*$ Significantly different from preexercise values; \#Significantly different from warm; $p \leq .05$.

\section{Technical Considerations of Blood Biomarkers for Exercise-Induced Oxidative Stress}

The four-biomarker panel of the current study was selected to encompass potential alterations in blood plasma antioxidant capacity and oxidative damage. This multiassay approach is beneficial in that the major redox facets of the complex redox milieu of blood plasma are represented (Buettner, 1993). The TEAC biomarker reflects both protein and nonprotein sulfhydryl antioxidants, while
FRAP is complementary in that it is sensitive to both aqueous- and lipid-phase antioxidants (Cao \& Prior, 1998). Lipid hydroperoxides and protein carbonyls were used as oxidative-damage markers in the current investigation. Given that oxidative stress was quantified within the blood plasma compartment, both protein carbonyls and lipid hydroperoxides have demonstrated sensitivities to exercise applications (Quindry et al., 2011; Quindry et al., 2003). To this end, these relatively stable oxidative biomarkers have half-lives that were well suited to the postexercise recovery period chosen currently. 


\section{Acute Exercise, Hyperthermia, and Blood Oxidative Stress}

Fatiguing exercise elicits consistent changes in blood redox markers (Bergholm et al., 1999; McAnulty et al., 2005; McAnulty et al., 2007; Quindry et al., 2008; Quindry et al., 2003), while the blood oxidative-stress response to moderate-intensity aerobic exercise is equivocal (Quindry et al., 2008; Quindry et al., 2003). In contrast, extended-duration aerobic exercise bouts performed at moderate intensity, including marathon and ultramarathon challenges, produce identifiable increases in blood biomarkers for oxidative stress (Bergholm et al., 1999; Liu et al., 1999; McAnulty et al., 2007). Examination of limited-duration moderateintensity exercise, however, is useful for understanding acute responses to routine exercise performed for health and fitness reasons. An exercise intensity of $60 \% \mathrm{VO}_{2 \max }$ was employed currently for this reason of applicability. In addition to exercise intensity, previous research indicates that warm environmental conditions can promote oxidative stress during moderate-intensity exercise (McAnulty et al., 2005). The current study extends on previous work, in that warm, room-temperature, and cold exercise conditions were examined. Current study design novelty also includes the fact that environmental influences were investigated during that 3 -hr exerciserecovery period.

Our finding that blood oxidative stress was significantly elevated during warm exercise recovery but not during cold or room-temperature trials supports previous findings. In a previous investigation, McAnulty et al. (2005) exercised human subjects on a treadmill at moderate intensity until core temperature reached 39.5 ${ }^{\circ} \mathrm{C}$. The hyperthermic exercise challenge produced an acute elevation in circulating levels of $\mathrm{F}_{2}$-isoprostanes. Heat-dependent effects on oxidative-damage biomarkers were observed in the current study for plasma lipid hydroperoxides but not protein carbonyls. Our finding that room-temperature exercise did not provoke statistically significant elevations in plasma lipid hydroperoxides supports previous observations after a similar exercise dose (Quindry et al., 2003). Given the complexity of the blood plasma, we cannot determine the source of the elevated lipid hydroperoxides in the current study. Based on previous investigations of hyperthermia (Laitano et al., 2010), there may be reason to suspect that exposure to higher temperatures in the warm trial recovery influenced plasma lipid hydroperoxides independent of exercise. Examination of plasma lipid hydroperoxides $1 \mathrm{hr}$ postexercise and corresponding core temperature $(r=.02)$, however, failed to reveal a statistical relationship. In support, McAnulty et al. (2005) observed a numerical rise in the plasma lipid hydroperoxides during room-temperature recovery from hyperthermic exercise. Follow-up studies should employ study designs that permit rapid reversal of exercise-induced hyperthermia to better delineate blood oxidative-stress responses to exercise versus recovery in hot environments.
In the current data set, we observed significant increases in both plasma FRAP and TEAC. These biometrics of antioxidant capacity are largely influenced in plasma by uric acid concentrations-approximately $60 \%$ and $20 \%$ for FRAP and TEAC, respectively (Cao $\&$ Prior, 1998). This rise in plasma uric acid reflects elevated purine metabolism during fatiguing exercise (Wayner, Burton, Ingold, Barclay, \& Locke, 1987). We previously identified increases in plasma FRAP and TEAC after high-intensity resistance-type exercise (Hudson et al., 2008), a response that was positively correlated with FRAP ( $r=.693$; Quindry et al., 2008). In the context of hyperthermic exercise and oxidative stress, few investigations have used TEAC and FRAP. In contrast to our observation of elevated TEAC, Gomes et al. (2011) observed a decrease in nasal-lavage TEAC after hyperthermic moderate- to high-intensity 8-km running. While differences between previous work and the current study may be due to variations in exercise duration (60 min vs. $32 \mathrm{~min}$ previously), it is more likely due to differences in biological sample location (blood plasma vs. nasal lavage previously).

\section{Study Implications, Conclusions, and Considerations for Future Research}

Current findings suggest that moderate-intensity exercise and postexercise recovery performed in warm environmental conditions are associated with increased blood oxidative stress compared with exercise performed in cooler environments. Current findings add to existing literature that links elevated environmental temperatures to exercise-induced oxidative stress (Gomes et al., 2011; Laitano et al., 2010; McAnulty et al., 2005). While some health and fitness professionals recommend antioxidant foods and supplements to quench exercise-induced oxidative stress, this approach contrasts recent paradigm shifts in understanding redox biology (Jones, 2006). The oxidative stress associated with moderate-intensity exercise is now recognized as an important adaptive stimulus to exercise (Gomez-Cabrera et al., 2005; Gomez-Cabrera et al., 2008; Ristow et al., 2009; Vina et al., 2006; Vina et al., 2000). The reader is referred to recent reviews that suggest that supplemental antioxidants are not currently warranted to combat exercise-induced oxidative stress (McGinley, Shafat, \& Donnelly, 2009; Powers, DeRuisseau, Quindry, \& Hamilton, 2004). In this regard, dietary intake of antioxidants was not quantified currently and stands as a study limitation to be remedied in future investigations.

Given recent shifts in scientific opinion regarding exercise-induced oxidative stress, it seems plausible that mild elevations in environmental temperature may contribute to exercise-induced adaptations, although this conclusion cannot be drawn from the current data set. While previous research details the impact of heat alone as a stimulus for oxidative stress (Mitchell \& Russo, 1983; Ohtsuka, Yabunaka, Fujisawa, Watanabe, \& Agishi, 1994), future research should examine the 
independent contribution of exercise-induced thermogenesis and ambient recovery temperatures on oxidative stress. The interplay of cytokine, oxidative stress, and metabolic signatures of blood plasma (Lewis et al., 2010) during hyperthermia should also be investigated as potential stimuli on muscle gene expression. In this regard, an eloquent study by Conti et al. (2012) found that endothelial cells exhibited variable survivability when cultured in plasma obtained from athletes performing aerobic, anaerobic, and mixed aerobic-anaerobic exercise.

\section{Acknowledgments}

This study was sponsored by Air Force Surgeon General \#FA7014-09-C-0010-P00001. The authors have no conflicts of interest to disclose. The results of the current study do not constitute endorsement by the American College of Sports Medicine.

\section{References}

Benzie, I.F., \& Strain, J.J. (1996). The ferric reducing ability of plasma (FRAP) as a measure of "antioxidant power": The FRAP assay. Analytical Biochemistry, 239(1), 70-76. PubMed doi:10.1006/abio.1996.0292

Bergholm, R., Makimattila, S., Valkonen, M., Liu, M-1., Lahdenpera, S., Taskinen, M-R., . . . Yki-Jarvinen, H. (1999). Intense physical training decreases circulating antioxidants and endothelium-dependent vasodilation. Atherosclerosis, 145, 341-349. PubMed doi:10.1016/ S0021-9150(99)00089-1

Bradford, M.M. (1976). A rapid and sensitive method for the quantitation of microgram quantities of protein utilizing the principle of protein-dye binding. Analytical Biochemistry, 72, 248-254. PubMed doi:10.1016/00032697(76)90527-3

Buettner, G.R. (1993). The pecking order of free radicals and antioxidants: Lipid peroxidation, alpha-tocopherol, and ascorbate. Archives of Biochemistry and Biophysics, 300(2), 535-543. PubMed doi:10.1006/abbi.1993.1074

Cao, G., \& Prior, R.L. (1998). Comparison of different analytical methods for assessing total antioxidant capacity of human serum. Clinical Chemistry, 44(6 Pt 1), 1309-1315. PubMed

Cao, G., Russell, R.M., Lischner, N., \& Prior, R.L. (1998). Serum antioxidant capacity is increased by consumption of strawberries, spinach, red wine or vitamin C in elderly women. The Journal of Nutrition, 128(12), 2383-2390. PubMed

Conti, V., Corbi, G., Russomanno, G., Simeon, V., Ferrara, N., Filippelli, W., . . Filippelli, A. (2012). Oxidative stress effects on endothelial cells treated with different athletes' sera. Medicine and Science in Sports and Exercise, 44(1), 39-49. PubMed doi:10.1249/MSS.0b013e318227f69c

Dill, D.B., \& Costill, D.L. (1974). Calculation of percentage changes in volumes of blood, plasma, and red cells in dehydration. Journal of Applied Physiology, 37(2), 247-248. PubMed
Frei, B., Stocker, R., \& Ames, B.N. (1988). Antioxidant defenses and lipid peroxidation in human blood plasma. Proceedings of the National Academy of Sciences of the United States of America, 85, 9748-9752. PubMed doi:10.1073/pnas.85.24.9748

Gomes, E.C., Stone, V., \& Florida-James, G. (2011). Impact of heat and pollution on oxidative stress and CC16 secretion after $8 \mathrm{~km}$ run. European Journal of Applied Physiology, 111(9), 2089-2097. PubMed doi:10.1007/s00421-0111839-x

Gomez-Cabrera, M.C., Borras, C., Pallardo, F.V., Sastre, J., Ji, L.L., \& Vina, J. (2005). Decreasing xanthine oxidasemediated oxidative stress prevents useful cellular adaptations to exercise in rats. The Journal of Physiology, 567(Pt 1), 113-120. PubMed doi:10.1113/jphysiol.2004.080564

Gomez-Cabrera, M.C., Domenech, E., \& Vina, J. (2008). Moderate exercise is an antioxidant: Upregulation of antioxidant genes by training. Free Radical Biology \& Medicine, 44(2), 126-131. PubMed doi:10.1016/j.freeradbiomed.2007.02.001

Hall, D.M., Buettner, G.R., Matthes, R.D., \& Gisolfi, C.V. (1994). Hyperthermia stimulates nitric oxide formation: electron paramagnetic resonance detection of NO-heme in blood. Journal of Applied Physiology (Bethesda, Md.), 77(2), 548-553. PubMed

Hudson, M.B., Hosick, P.A., McCaulley, G.O., Schrieber, L., Wrieden, J., McAnulty, S.R., . . Quindry, J.C. (2008). The effect of resistance exercise on humeral markers of oxidative stress. Medicine and Science in Sports and Exercise, 40(3), 542-548. PubMed doi:10.1249/ MSS.0b013e31815daf89

Jones, D.P. (2006). Disruption of mitochondrial redox circuitry in oxidative stress. Chemico-Biological Interactions, 163(1-2), 38-53. PubMed doi:10.1016/j.cbi.2006.07.008

Laitano, O., Kalsi, K.K., Pook, M., Oliveira, A.R., \& GonzalezAlonso, J. (2010). Separate and combined effects of heat stress and exercise on circulatory markers of oxidative stress in euhydrated humans. European Journal of Applied Physiology, 110(5), 953-960. PubMed doi:10.1007/ s00421-010-1577-5

Lewis, G.D., Farrell, L., Wood, M.J., Martinovic, M., Arany, Z., Rowe, G.C., . . Gerszten, R.E. (2010). Metabolic signatures of exercise in human plasma. Science Translational Medicine, 2(33), 33-37. PubMed doi:10.1126/ scitranslmed.3001006

Liu, M-L., Bergholm, R., Makitmattila, S., Lahdenpera, S., Valkonen, M., Hilden, H., . . Taskinen, M-R. (1999). A marathon run increase the susceptibility of LDL to oxidation in vitro and modifies plasma antioxidants. The American Journal of Physiology, 276, E1083-E1091. PubMed

McAnulty, S.R., McAnulty, L., Pascoe, D.D., Gropper, S.S., Keith, R.E., Morrow, J.D., \& Gladden, L.B. (2005). Hyperthermia increases exercise-induced oxidative stress. International Journal of Sports Medicine, 26(3), 188-192. PubMed doi:10.1055/s-2004-820990

McAnulty, S.R., Owens, J.T., McAnulty, L.S., Nieman, D.C., Morrow, J.D., Dumke, C.L., \& Milne, G.L. (2007). Ibuprofen use during extreme exercise: Effects on oxidative stress and PGE2. Medicine and Science in Sports 
and Exercise, 39(7), 1075-1079. PubMed doi:10.1249/ mss.0b13e31804a8611

McGinley, C., Shafat, A., \& Donnelly, A.E. (2009). Does antioxidant vitamin supplementation protect against muscle damage? Sports Medicine (Auckland, N.Z.), 39(12), 10111032. PubMed doi:10.2165/11317890-000000000-00000

Mitchell, J.B., \& Russo, A. (1983). Thiols, thiol depletion, and thermosensitivity. Radiation Research, 95(3), 471-485. PubMed doi:10.2307/3576094

Nourooz-Zadeh, J., Tajaddini-Sarmadi, J., \& Wolff, S.P. (1994). Measurement of plasma hydroperoxide concentrations by the ferrous oxidation-xylenol orange assay in conjunction with triphenylphosphine. Analytical Biochemistry, 220(2), 403-409. PubMed doi:10.1006/abio.1994.1357

Ohtsuka, Y., Yabunaka, N., Fujisawa, H., Watanabe, I., \& Agishi, Y. (1994). Effect of thermal stress on glutathione metabolism in human erythrocytes. European Journal of Applied Physiology and Occupational Physiology, 68(1), 87-91. PubMed doi:10.1007/BF00599247

Powers, S.K., DeRuisseau, K.C., Quindry, J., \& Hamilton, K.L. (2004). Dietary antioxidants and exercise. Journal of Sports Sciences, 22(1), 81-94. PubMed doi:10.1080/0264041031000140563

Quindry, J., Miller, L., McGinnis, G., Irwin, M., Dumke, C., Magal, M., . . . Urbiztondo, Z. (2011). Muscle-fiber type and blood oxidative stress after eccentric exercise. International Journal of Sport Nutrition and Exercise Metabolism, 21(6), 462-470. PubMed

Quindry, J.C., McAnulty, S.R., Hudson, M.B., Hosick, P., Dumke, C., McAnulty, L.S., . . . Nieman, D. (2008). Oral quercetin supplementation and blood oxidative capacity in response to ultramarathon competition. International Journal of Sport Nutrition and Exercise Metabolism, 18(6), 601-616. PubMed

Quindry, J.C., Stone, W.L., King, J., \& Broeder, C.E. (2003). The effects of acute exercise on neutrophils and plasma oxidative stress. Medicine and Science in Sports and Exercise, 35(7), 1139-1145. PubMed doi:10.1249/01. MSS.0000074568.82597.0B

Ristow, M., Zarse, K., Oberbach, A., Kloting, N., Birringer, M., Kiehntopf, M., ... Bluher, M. (2009). Antioxidants prevent health-promoting effects of physical exercise in humans. Proceedings of the National Academy of Sciences of the United States of America, 106(21), 8665-8670. PubMed doi:10.1073/pnas.0903485106

Salo, D.C., Donovan, C.M., \& Davies, K.J. (1991). HSP70 and other possible heat shock or oxidative stress proteins are induced in skeletal muscle, heart, and liver during exercise. Free Radical Biology \& Medicine, 11(3), 239-246. PubMed doi:10.1016/0891-5849(91)90119-N

Slivka, D.R., Dumke, C.L., Tucker, T.J., Cuddy, J.S., \& Ruby, B. (2012).Human mRNA response to exercise and temperature. International Journal of Sports Medicine, 33(2), 94-100. PubMed doi:10.1055/s-0031-1287799

Vina, J., Borras, C., Gomez-Cabrera, M.C., \& Orr, W.C. (2006). Part of the series: From dietary antioxidants to regulators in cellular signalling and gene expression. Role of reactive oxygen species and (phyto) oestrogens in the modulation of adaptive response to stress. Free Radical Research, 40(2), 111-119. PubMed doi:10.1080/10715760500405778

Vina, J., Gomez-Cabrera, M.C., Lloret, A., Marquez, R., Minana, J.B., Pallardo, F.V., \& Sastre, J. (2000). Free radicals in exhaustive physical exercise: Mechanism of production, and protection by antioxidants. IUBMB Life, 50(4-5), 271-277. PubMed doi:10.1080/15216540051080994

Wayner, D.D.M., Burton, G.W., Ingold, K.U., Barclay, L.R.C., \& Locke, S.J. (1987). The relative contribution of vitamin $\mathrm{E}$, urate, ascorbate and proteins to the total paroxyl radicaltrapping antioxidant activity of human blood plasma. Biochimica et Biophysica Acta, 924, 408-419. PubMed doi:10.1016/0304-4165(87)90155-3 